\title{
Mean Age of First Sex: Do They Know What We Mean?
}

\author{
Jokin de Irala $\cdot$ Alfonso Osorio $\cdot$ Silvia Carlos • \\ Miguel Ruiz-Canela $\cdot$ Cristina López-del Burgo
}

Published online: 27 May 2011

(C) The Author(s) 2011. This article is published with open access at Springerlink.com

Early age at first sexual intercourse is a particularly important variable for public health policy makers. It is associated with specific unhealthy behaviors, such as having unprotected sex on first sexual intercourse, condom misuse or having multiple (concurrent or lifetime) partners (Kaestle, Halpern, Miller, \& Ford, 2005; Louie et al., 2009). These can lead to higher rates of sexually transmitted infections (STIs), teenage pregnancy, and adverse psychological consequences, such as feelings of disappointment and regret (Campbell, 2008; CDC, 2008; Eshbaugh \& Gute, 2008; Ma et al., 2009; Vaccarella et al., 2006; Wight et al., 2008).

In the light of the role played by the delay of first sexual intercourse and mutual monogamy in curtailing STI epidemics (Halperin et al., 2011; Potts et al., 2008), the Joint United Nations Program on HIV/AIDS (UNAIDS) has introduced changes in its yearly reports on the global AIDS epidemic: in addition to condom use, they now report age of sexual initiation and multiple

J. de Irala $(\bowtie) \cdot S$. Carlos · C. López-del Burgo

Preventive Medicine and Public Health, School of Medicine,

University of Navarra, 31080 Pamplona, Spain

e-mail: jdeirala@unav.es

A. Osorio

Department of Education, University of Navarra, Pamplona, Spain

M. Ruiz-Canela

Department of Biomedical Humanities, University of Navarra,

Pamplona, Spain

J. de Irala $\cdot$ A. Osorio $\cdot$ S. Carlos · M. Ruiz-Canela

C. López-del Burgo

Institute of Culture and Society, University of Navarra,

Pamplona, Spain partnerships in different countries as a means of more comprehensively following up on all the determinants of the epidemic (UNAIDS, 2006, 2008).

However, the information concerning age of sexual initiation can be conveyed in different ways. For instance, UNAIDS usually reports the "proportion, among 15-19-year-olds, having had sex by age 15"(UNAIDS, 2008) whereas other sources use the "mean age at first sexual intercourse" alone or in combination with "proportions having already had sex at given ages" (Avery \& Lazdane, 2008; Kaestle et al., 2005; Manlove, Ikramullah, Mincieli, Holcombe, \& Danish, 2009; Rosenbaum, 2009). Average ages at first sexual intercourse lack precision in describing the extent of sexual experience at different ages. They are sensitive to extreme values and sensitive to the ranges of ages of the persons included in the survey. For example, a plausible wrong interpretation of the statement that "the mean age of sexual initiation is 15 years" is that "most youth" aged 15 are having sex when, in fact, the contrary may be true. Average ages at first sexual intercourse, obtained from published epidemiological studies about sexuality, are often conveyed by the media in such a way that it does not necessarily grasp the subtleties entailed in such data. The targets of media, such as the general population and indeed young people themselves, can, in turn, be misled. Sentences derived from average data such as this one-“"compared with previous generations, young people (16-20 year-olds) were having intercourse for the first time at an earlier age, on average at 16.5 years of age" (Avery \& Lazdane, 2008) - leave the facts as to how many from these age groups have, in fact, had sex unspecified. These confusing interpretations of epidemiological data create definite impressions that can be misleading and thus may hinder public health and educational interventions that are trying to delay sexual initiation in youth (Halperin et al., 2004). As Rose (1992) affirmed years ago, "It doesn't make much sense to expect that individuals will behave differently from their peers; 
it is more appropriate to change the general norms of behavior and the circumstances that facilitate these changes."

Data from an ongoing international study which examines what youth think and feel about relationships, love, and sexuality were used to show that this confusion is indeed possible (Project YOURLIFE). Specific details on the data collection process for this project are described elsewhere (de Irala et al., 2009). Briefly, project YOURLIFE is a cross-sectional survey that is being implemented in different countries through a multi-stage sampling of clusters representative of public and private schools within participating countries. A questionnaire was used to gather information on sociodemographic data, characteristics of the group of friends, use of free time, access and exposure to media, feelings, opinions, and information sources on relationships, love, and sexuality, and life goals.

In order to compare "mean" ages of first sexual intercourse and "proportions" of youth sexually experienced at different ages, data from El Salvador, Peru, and Spain were used $(N=$ 7011; see Table 1). Country specific "mean ages of sexual initiation" are presented together with their corresponding "proportions of youth having had sex at different ages" in order to show how different interpretations might be conveyed when using one or the other. Mean ages were estimated using three different age ranges to allow for a sensitivity analysis: (1) the age ranges actually available in each study site, (2) the closest possible ranges to the 15-19 range used by UNAIDS, and (3) the age range that was common to the three countries whose data we used.

In all the estimations of mean age of first sexual intercourse presented in the table, the actual mean value is compatible with the fact that the majority of youth whose ages are close to that mean value have not had sex yet. The use of means could, therefore, be conveying a wrong message. In fact, less than $25 \%$ of youth with ages close to the mean were sexually initiated in all countries of the table shown. The mean age of first sexual intercourse was obviously estimated solely using subjects who have already had sexual intercourse whereas the proportion of youth that were sexually initiated use all youth in each age group as the denominator. In all cases, the most accurate and least misleading information to know the extent of sexual initiation at a given age seems to be the percentage sexually active at different ages.

Some authors use mean ages of sexual initiation with shorter age intervals (Ma et al., 2009). This has the advantage of obtaining mean ages that are closer to the ages examined in the age interval but does not eliminate the misleading effect of conveying that "most" youth of those ages have had sex when the contrary

Table 1 Age of first sexual intercourse of youth from El Salvador, Peru, and Spain (Project YOURLIFE) using different statistics

\begin{tabular}{|c|c|c|c|c|}
\hline \multirow[t]{2}{*}{ Country } & \multirow{2}{*}{$\begin{array}{l}\text { Percent sexually active } \\
\text { at different ages }{ }^{\text {a }} \\
\text { Age }(\%)\end{array}$} & \multicolumn{3}{|c|}{ Mean and Median age of first sexual intercourse using different ranges ${ }^{b}$} \\
\hline & & $\begin{array}{l}\text { Range of each study venue } \\
\text { (age range) }\end{array}$ & $\begin{array}{l}\text { Range closest to } 15-19^{c} \\
\text { (age range) }\end{array}$ & $\begin{array}{l}\text { Range common to three } \\
\text { countries (age range) }\end{array}$ \\
\hline \multirow{7}{*}{$\begin{array}{l}\text { El Salvador } \\
\qquad(N=2,810)\end{array}$} & $13(6.7)$ & (13-19) & (15-19) & $(16-18)$ \\
\hline & $14(13.8)$ & Mean: 14.8 & Mean: 15.2 & Mean: 15.3 \\
\hline & $15(20.9)$ & Median: 15 & Median: 15 & Median: 15 \\
\hline & $16(26.6)$ & & & \\
\hline & $17(32.0)$ & & & \\
\hline & $18(38.0)$ & & & \\
\hline & $19(45.5)$ & & & \\
\hline \multirow[t]{6}{*}{ Peru $(N=3,399)$} & $13(4.4)$ & $(13-18)$ & $(15-18)$ & $(16-18)$ \\
\hline & $14(9.6)$ & Mean: 14.3 & Mean: 14.5 & Mean: 14.8 \\
\hline & $15(17.0)$ & Median: 15 & Median: 15 & Median: 15 \\
\hline & $16(21.4)$ & & & \\
\hline & $17(29.4)$ & & & \\
\hline & $18(40.0)$ & & & \\
\hline \multirow[t]{5}{*}{ Spain $(N=802)$} & $16(21.7)$ & $(16-20)$ & $(16-19)$ & $(16-18)$ \\
\hline & $17(34.8)$ & Mean: 16.3 & Mean: 16.2 & Mean: 15.8 \\
\hline & $18(62.9)$ & Median: 16 & Median: 16 & Median: 16 \\
\hline & $19(78.0)$ & & & \\
\hline & $20(79.5)$ & & & \\
\hline
\end{tabular}


is true, as is the case with our Spanish data in the table, with short age intervals.

The extensive use of mean age of sexual initiation in the scientific literature and consequently in the media suggests that the potential for misleading interpretations is not being adequately taken into account. Studies that use mean age of sexual initiation usually use age ranges that do not take into account those who have first sex at older ages or who never have had sex at all. This essentially biases the interpretation of such means.

The data presented in the table clearly show that the percentage of youth sexually active can be quite low at ages that are close to the mean age of sexual initiation and confirm that the use of this mean can be misleading and that misinterpretation of data is, indeed, quite plausible when using such average ages of sexual initiation. This finding was robust and remained unchanged when different age ranges were used to estimate the means. The data used to estimate these percentages and means are not artificial and come from different countries using similar survey methodologies. Furthermore, these data were representative of the students from the respective countries. However, the percentage of youth sexually active will always tend to be quite low at ages that are close to the mean age of first sexual intercourse with whatever data commonly used in epidemiological studies targeting youth. The distribution of the mean age of first sexual intercourse is always skewed in the context of such studies. The mean age of first sexual intercourse will, therefore, never be consistent with "most youth close to that age having already had sex."

To our knowledge, no one has shown using real data that the use of mean age of sexual initiation can be misleading, especially when this information is portrayed without also specifying the percentage sexually active at each age. A more precise depiction of trends and displaying percentages to target audiences provides the clearest picture and can be of crucial help to health policy makers and health education managers who are trying to convey the importance of delaying sexual initiation among youth. We therefore encourage the use of the percentage of youth, at different ages, who have already initiated sexual relationships instead of the use of averages. This will reduce confusion, help avoid erroneous interpretations, and provide a much needed additional source of support to young people, all of which in turn gives such public health policies a better chance of succeeding.

Acknowledgments This work was partially supported by Intermedia Consulting (Italy), Concultura (El Salvador), the University of Piura (Peru), the University of Navarra and the Government of Navarra [project 24/2007] (Spain). We thank Matthew Hanley, for reviewing the English version of this letter, and Professor Miguel Delgado Rodríguez for his insights.

Open Access This article is distributed under the terms of the Creative Commons Attribution Noncommercial License which permits any noncommercial use, distribution, and reproduction in any medium, provided the original author(s) and source are credited.

\section{References}

Avery, L., \& Lazdane, G. (2008). What do we know about sexual and reproductive health of adolescents in Europe? European Journal of Contraception Reproductive Health Care, 13, 58-70.

Campbell, A. (2008). The morning after the night before: Affective reactions to one-night stands among mated and unmated women and men. Human Nature, 19, 157-173.

Centers for Disease Control and Prevention. (2008). Nationally representative CDC study finds 1 in 4 teenage girls has a sexually transmitted disease. Retrieved June 29, 2010 from www.cdc.gov/std conference/2008/press/release-11march2008.htm.

de Irala, J., Osorio, A., López del Burgo, C., Belen, V. A., de Guzman, F. O., Calatrava, M., et al. (2009). Relationships, love and sexuality: What the Filipino teens think and feel. BMC Public Health, 9, 282.

Eshbaugh, E. M., \& Gute, G. (2008). Hookups and sexual regret among college women. Journal of Social Psychology, 148, 77-89.

Halperin, D. T., Mugurungi, O., Hallett, T. B., Muchini, B., Campbell, B., Magure, T., et al. (2011). A surprising prevention success: Why did the HIV epidemic decline in Zimbabwe? PLoS Medicine, 8(2), e1000414.

Halperin, D. T., Steiner, M. J., Cassell, M. M., Green, E. C., Hearst, N., Kirby, D., et al. (2004). The time has come for common ground on preventing sexual transmission of HIV. Lancet, 364, 1913-1915.

Kaestle, C. E., Halpern, C. T., Miller, W. C., \& Ford, C. A. (2005). Young age at first sexual intercourse and sexually transmitted infections in adolescents and young adults. American Journal of Epidemiology, 161, 774-780.

Louie, K. S., de Sanjose, S., Diaz, M., Castellsague, X., Herrero, R., Meijer, C. J., et al. (2009). Early age at first sexual intercourse and early pregnancy are risk factors for cervical cancer in developing countries British. Journal of Cancer, 100, 1191-1197.

Ma, Q., Ono-Kihara, M., Cong, L., Xu, G., Pan, X., Zamani, S., et al. (2009). Early initiation of sexual activity: A risk factor for sexually transmitted diseases, HIV infection, and unwanted pregnancy among university students in China. BMC Public Health, 9, 111.

Manlove, J., Ikramullah, E., Mincieli, L., Holcombe, E., \& Danish, S. (2009). Trends in sexual experience, contraceptive use, and teenage childbearing: 1992-2002. Journal of Adolescent Health, 44, 413-423.

Potts, M., Halperin, D. T., Kirby, D., Swidler, A., Marseille, E., Klausner, J. D., et al. (2008). Reassessing HIV prevention. Science, 320, 749750 .

Rose, G. (1992). The strategy of preventive medicine. Oxford: Oxford University Press.

Rosenbaum, J. E. (2009). Patient teenagers? A comparison of the sexual behavior of virginity pledgers and matched nonpledgers. Pediatrics, 123(1), e110-e120.

UNAIDS. (2006). 2006 Report on the global AIDS epidemic. Retrieved June 29, 2010, from http://www.unaids.org/en/KnowledgeCentre/ HIVData/GlobalReport/2006/default.asp.

UNAIDS. (2008). 2008 Report on the global AIDS epidemic. Retrieved June 29, 2010, from http://www.unaids.org/en/KnowledgeCentre/ HIVData/GlobalReport/2008/2008_Global_report.asp.

Vaccarella, S., Franceschi, S., Herrero, R., Munoz, N., Snijders, P. J., Clifford, G. M., et al. (2006). Sexual behavior, condom use, and human papillomavirus: Pooled analysis of the IARC human papillomavirus prevalence surveys. Cancer Epidemiology, Biomarkers and Prevention, 15, 326-333.

Wight, D., Parkes, A., Strange, V., Allen, E., Bonell, C., \& Henderson, M. (2008). The quality of young people's heterosexual relationships: A longitudinal analysis of characteristics shaping subjective experience. Perspectives on Sexual and Reproductive Health, 40, 226-237. 